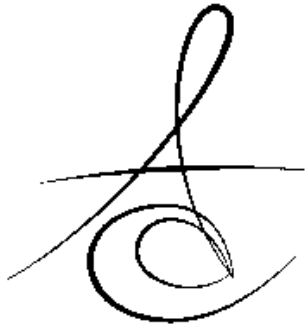

Makale Kodu/Article code: 1756

Makale Gönderilme tarihi: 27.06 .2014

Kabul Tarihi: 18.11.2014

\section{OTOTRANSPLANTASYON: LİTERATÜR DERLEMESİ}

\section{AUTOTRANSPLANTATION: REVIEW OF THE LITERATURE}

\author{
Arş. Gör. Dt. Nesrin SARUHAN*
}

Yrd. Doç. Dr. Adnan KILINÇ*

\author{
Prof. Dr. Ümit ERTAŞ* \\ Arş. Gör. Dt. Tahsin TEPECİK*
}

\section{ÖZET}

Diş eksikliklerinde implantlar uzun dönem başarıları ile tatmin edici hasta konforu sağlasa da diş eksikliği ve gömülü diş varlığı gibi bazı durumlarda ototransplantasyon bir tedavi seçeneği olarak tercih edilebilir. Yine gömülü dişler, özellikle de maksiller kaninler ortodontik tedavi ile sürdürülebilir durumda olduğu zaman, hastalar ekonomik, süre ve diğer nedenlerle ortodontik tedavi istemediklerinde, ototransplantasyon düşünülebilir. Estetiği iyileştirmesi, normal alveol ve fasiyal gelişimi devam ettirmesi, ark bütünlüğünü, fonetiği ve oklüzyonu ve implantlarda olmayan propriosepsiyon duyusunu sağlaması bakımından birçok avantajları vardır. Ayrıca ekonomik olarak uygun ve diş eksikliğinin en hızlı tedavi metodudur. Ototransplantasyon gerekli prognostik faktörlere dikkat edildiğinde başarısı yüksek bir tedavi yöntemidir.

Bu literatür derlemesinde, ototransplantasyonun başarı oranları, prognostik faktörleri ve komplikasyonları ile uygulanan farklı tedavi yöntemleri sunulmaktadır.

Anahtar Kelimeler: Transplantasyon; Gömülü diş, Literatür derleme

\section{ABSTRACT}

With the long term success of the dental implants which provide satisfactory patient comfort, in some situations autotransplantation may be the choice of treatment for missing and impacted tooth. Again impacted teeth, especially the maxillary canines if they can be treated with orthodontics but the patient does not want it because of economic insufficiency or lack of time etc. autotransplantation can be considered. Because it improves aesthetics; allows normal alveolar and facial growth; maintains arch integrity, phonetics, occlusion and the sense of proprioception which dental implants do not have, it has many advantages. Besides, it is economically viable and fastest way to replacing missing tooth. Autotransplantation has high success rate if the prognostic factors taken into consideration.

In this literatüre review, autotransplantation with aspects of success rates, prognostic factors, complications and different treatment methods were presented.

Key Words: Transplantation; Impacted tooth, Review Literature as Topic

\section{GİRIş}

Uygun bir donör diş varlığında, ototransplantasyon ark bütünlüğü ve diş eksikliğini gidermenin alternatif bir yoludur. Kısaca, gömülü veya sürmüş bir dişin, aynı bireyin dişsiz bölgesine nakli olarak tanımlanabilir. ${ }^{1,2}$ Günümüzde, kök gelişimi, kök rezorpsiyonu, periodonsiyumun canlılığı gibi fizyolojik durumlar hakkındaki genel bilgi ve kavrayışın artmasına bağlı olarak, başarı oranı \%90'lar seviyesindedir. ${ }^{1-3,4-8}$
$\mathrm{Bu}$ literatür derlemesinde, ototransplantasyon tedavisinin başarı oranları, prognoz üzerine etki eden faktörleri ve yeni tedavi yaklaşımları sunulmaktadır.

\section{Tarihçe}

İlk otojen diş transplantasyonları literatürde 1950'lerde görülmüştür ve başarı oranları da yaklaşık \%50 seviyelerinde kalmıştır. Bu durum, o dönemde diş kök gelişim fizyolojisi ve kök rezorpsiyonu sürecinin iyi bilinmemesi ile açıklanabilir. ${ }^{1-3} \quad 2000$ 'li yıllarda periodontal dokuların, periodontal ligamentin ve kök rezorpsiyonunun iyileşmesi ile ilgili birçok klinik araştırma yapılmış, ve bu bilgilere dayanılarak, diş transplantasyonu başarısı da artmıştır.7, 9 Başarının 
Atatürk Üniv. Diş Hek. Fak. Derg.

] Dent Fac Atatürk Uni

Supplement: 11, Yıl: 2015, Sayfa : 114-122
SARUHAN, ERTAŞ, KILINÇ, TEPECIKK artması birçok klinisyen ve profesyonelin ilgisini bu alana çekmiştir, fakat aynı zamanda çoğu profesyonel, gerek geçmişteki başarısızlıklardan gerekse öğrenim süreçlerinde etkili olan öğretim üyelerinin kötü tecrübelerinden etkilenerek, diş ototransplantasyonlarına karşı mesafeli durmakta ve bu tedavi seçeneğini, birçok avantajına rağmen etkili bir tedavi metodu olarak görmemektedir. ${ }^{9}$, 10 Bu durum, tedavi yöntemi ile ilgili eksik bilgi ve geçmişte üzerinde pek durulmayan klinik faktörlerin bir sonucu olabilmektedir.

\section{Klinik değerlendirme ve endikasyonla}

Gömülü, yarı gömülü veya sürmüş dişler; aynı bireyin dişsiz bölgelerine transplante edilebilir. Literatür incelendiğinde, ototransplantasyonun, genç hastalarda daha başarılı olduğu farkedilmektedir. ${ }^{11-14}$ Bu durumun sebebi çoğunlukla, genç hastaların donör dişlerinin, yaşlı hastalara göre kök gelişimi sürecini henüz tamamlamamış olması ve pulpa canlıı̆ı̆ını kaybetmemesi olarak açıklanabilmektedir. ${ }^{15} \mathrm{Bu}$ nedenle genç hastalarda ototransplantasyonun bir tedavi seçeneği olarak dikkate alınması gerekmektedir. Öte yandan literatürde, saptanan başarı kriterlerine göre başarılı bulunan kök gelişimini tamamlamış dişlerle yapılan birçok vaka raporu ve serisi de bulunmaktadır. $^{5-7,} 11,13 \mathrm{Bu}$ nedenle kök gelişimi tamamlanmış dişlerde de tedavi göz ardı edilmemelidir. Klinik değerlendirmede dikkate alınacak bir başka faktör de gerek transplante edilecek dişin, gerekse alıcı soketin durumudur. Transplante edilecek dişin kök morfolojisi basit olmalı ve sağıklı bir periodontal membrana sahip olmalıdır. Alıc yatakta ise enfeksiyon olmamalıdır. Travma ve transplante edilecek dişin dış ortamda kalma süresinin de minimize edilmesi gerekmektedir. ${ }^{16-18}$ Teorik olarak, transplante edilecek dişin kök morfolojisi alıcı yatakta hafif değişiklikler yapılarak uyumlandırılabiliyorsa ve transplante diş kronunun alıcı bölgenin karşıt arkındaki dişle oklüzyonu ve genel estetiği restoratif bir yöntemle düzeltilebiliyorsa herhangi bir diş, herhangi bir sokete transplante edilebilir kanaatindeyiz. Fakat literatürde, ototransplantasyon tedavilerinde çoğunlukla benzer endikasyon kalıpları izlenmiştir. Cross D. ve arkadaşları, bu endikasyonları şöyle sıralamaktadır;

1. Anterior maksiller diş veya dişlerin travma veya patolojik bir durum nedeniyle kaybı durumunda, mandibuler ikinci premolarların transplantasyon için seçilmesi.
2. Maksiller ikinci premolarların, mandibuler ikinci premolar yokluğunda kullanılması gibi, bir arkta bir veya iki diş hipodontisi olup, karşıt arkta çapraşıklık görülen vakalar.

3. Konvansiyonel yöntemle cerrahi olarak ekspoze edilip, ortodontik seviyeleme uygulanamayacak ektopik durumdaki kaninlerin ototransplantasyonu örneğinde görüldüğü gibi, ektopik pozisyonlanmış dişlerin, doğru konumlarına transplante edilmesi.

4. Umutsuz prognoza sahip birinci molarların çekilip, gelişmekte olan üçüncü molarlar ile transplante edilmesi. $^{19}$

\section{Avantajlar ve dezavantajlar}

Otojen diş transplantasyonlarının avantajları ve dezavantajları, diş eksikliğinin diğer tedavi yöntemleri ile karşılaştırılmalıdır. Otojen diş transplantasyonları ile birlikte bir seçenek olarak düşünülmesi gereken endoosseoz implantlar bu tedavi yöntemlerinden biridir. Dental implantların başarı oranları ototransplante dişlerden yüksek olmasına rağmen, başarılı ototransplante dişler implantlara karşı bir avantaj olarak periodontal ligament canlılığını koruyabilir ve kemik rejenerasyonunu uyarabilirler. Bu durum bu tedavi seçeneğini büyüme gelişme dönemindeki çocuklar için eşsiz kılar. Özellikle kök gelişimi tamamlanmamış dişlerde kök gelişimi olması gereken biçimde sürebilir. Başarılı ototransplante dişler proprioseptif duyu algısına sahiptirler ve normal bir diş gibi fonksiyon gösterebilirler. Transplante dişlere daha sonra ortodontik kuvvetler uygulanabilir. Ayrıca ototransplantasyon tedavi masrafları, dental implantlara göre oldukça düşüktür ve hasta için ekonomik bir tedavi seçeneğidir. ${ }^{10,19,20}$ Bu özellikler incelendiğinde görülecektir ki, başarılı ototransplante dişler, canlı bir dişin, implantlara karşı koruduğu çoğu özelliklere sahiptir.

Ototransplantasyon tedavisinin dental implantlara karşı en belirgin dezavantajları, başarı oranlarının implantlara göre düşük olmasıdır. Fakat yine de yayınlanmış vaka serilerindeki başarı oranları diğer tedavi seçenekleri ile karşılaştırılabilecek düzeydedir (Bkz. Tablo 1.). Kök gelişimi tamamlanmamış dişlerle yapılan bazı ototransplantasyon vaka serileri başarı oranının \%100 olarak belirtmiş olmalarına rağmen, bu çalışmaların zayıflığı örnek büyüklüklerinin az olmasıdır. ${ }^{21,22}$ Ototransplantasyon tedavisinin belki de en büyük handikapı, cerrahi tekniğin çok hassas ve 
Tablo 1. Yapılan Çalışmalarda Elde Edilen Başarı Oranları

\begin{tabular}{|c|c|c|c|c|c|c|c|}
\hline & $\begin{array}{c}\text { Başarı } \\
\text { Yüzdesi }\end{array}$ & $\begin{array}{l}\text { Hayatta } \\
\text { kalma } \\
\text { Yüzdesi }\end{array}$ & $\begin{array}{l}\text { Takip } \\
\text { etme } \\
\text { süresi }\end{array}$ & $\begin{array}{l}\text { Örnek } \\
\text { boyutu }\end{array}$ & $\begin{array}{l}\text { Transplante diş } \\
\text { tipi }\end{array}$ & $\begin{array}{l}\text { Kanal tedavisine } \\
\text { başlama zamanı }\end{array}$ & $\begin{array}{l}\text { Splint materyali ve splint } \\
\text { süresi }\end{array}$ \\
\hline $\begin{array}{c}\text { Jonsson ve } \\
\text { Sigurdsson, } \\
2004 \\
\end{array}$ & $\% 92.5$ & $\% 97.5$ & $\begin{array}{c}\text { Ortalama } \\
10 \text { yıl. }\end{array}$ & 40 & $\begin{array}{l}\text { Açık ve kapalı } \\
\text { apeksli dişler. }\end{array}$ & $\begin{array}{c}\text { Kapalı apeksli dişlere } 4 \\
\text { hafta içinde. }\end{array}$ & $\begin{array}{c}\text { 4-0 Naylon sütur ile } 10-12 \\
\text { gün }\end{array}$ \\
\hline Bae ve ark., ${ }^{6} 2010$ & $\% 84$ & - & $\begin{array}{c}\text { Ortalama } \\
15 \text { ay. }\end{array}$ & 19 & $\begin{array}{l}\text { Kapalı apeksli } \\
\text { dişler }\end{array}$ & $\begin{array}{c}6 \text { Hastada } \\
\text { transplantasyondan } \\
\text { önce, } 13 \text { hastada } 1 \text { ila } 2 \\
\text { hafta sonra. }\end{array}$ & $\begin{array}{c}2 \text { ila } 3 \text { hafta tel veya fiber } \\
\text { splintlerle }\end{array}$ \\
\hline $\begin{array}{c}\text { Meja`re ve ark.. } \\
2004\end{array}$ & - & $\% 81$ & $\begin{array}{l}10 \text { yıla } \\
\text { kadar. }\end{array}$ & 47 & $\begin{array}{l}\text { Kapalı apeksli } \\
\text { dişler. }\end{array}$ & 4 hafta içinde. & $\begin{array}{c}10 \text { diş Luxatemp } \\
\circledR(D M 6, \text { Hamburg, } \\
\text { Germany) ile geri kalan } \\
\text { dişler sütur ile } 10 \text { gün } \\
\text { boyunca }\end{array}$ \\
\hline $\begin{array}{c}\text { Akkocaoglu ve } \\
\text { Kasaboglu, }{ }^{8} \\
2005 \\
\end{array}$ & $\% 85$ & - & $\begin{array}{c}\text { Ortalama } \\
9 \text { yıl. }\end{array}$ & 96 & $\begin{array}{l}\text { Kapalı apeksli } \\
\text { dişler. }\end{array}$ & $\begin{array}{l}\text { 3. ayın sonunda, } \\
\text { patolojik bulgu } \\
\text { görülürse. }\end{array}$ & $\begin{array}{c}\text { Herhangi bir splint } \\
\text { materyali kullanılmamış. }\end{array}$ \\
\hline $\begin{array}{l}\text { Czochrowska } \\
\text { ve ark., }{ }^{4} 2002\end{array}$ & $\% 79$ & $\% 90$ & $\begin{array}{l}41 \text { yila } \\
\text { kadar. }\end{array}$ & 30 & $\begin{array}{l}\text { Açık apeksli } \\
\text { dişler. }\end{array}$ & $\begin{array}{c}\text { Endodontik tedavi } \\
\text { yapılmamış. }\end{array}$ & - \\
\hline $\begin{array}{l}\text { Gonnissen ve } \\
\text { ark., }{ }^{14}\end{array}$ & $\% 57.5$ & $\% 75.3$ & $\begin{array}{l}\text { Ortalama } \\
11 \text { yıl. }\end{array}$ & 73 & $\begin{array}{l}\text { Açık ve kapalı } \\
\text { apeksli dişler. }\end{array}$ & $\begin{array}{l}\text { Zaman belirtilmemiş. } \\
\text { Kapalı apeksli dişlere } \\
\text { uygulanmış, diğer } \\
\text { dişlere, semptom } \\
\text { görüldüğünde } \\
\text { başlanmış. } \\
\end{array}$ & $\begin{array}{l}\text { Sütur, asid-etch kompozit } \\
\text { veya ortodontik tel ile. } \\
\text { Zaman belirtilmemiş. }\end{array}$ \\
\hline
\end{tabular}

karmaşık olması ve başarı için birçok kritere dikkat edilmesi gerektiği gerçeğidir. ${ }^{10,23} \mathrm{Bu}$ kriterler başlıca şu şekilde maddelenebilir;

a. Transplante edilecek dişlerin sağlıklı bir periodontal membrana sahip olması gerekmektedir. ${ }^{11,16-20,24}$

b. Alıcl sokette herhangi bir enfeksiyon bulgusunun bulunmaması gerekir. ${ }^{16-18}$

c. Transplante edilecek dişler, zayıf bir kuvvetle çekilebilmeli ve travma minimize edilmelidir. ${ }^{16-18}$

d. Transplante edilecek dişlerin, basit kök morfolojisine sahip olması gerekir. ${ }^{16-18}$

e. Transplante edilecek dişler dış ortamda uzun süre kalmamalı ve Hertwig epitel kök kılıfına (Hertwig Epithelial Root Sheath-HERS) zarar verilmemelidir. ${ }^{18,22,25} \mathrm{Bu}$ nedenle, mümkünse bilgisayar destekli hızlı prototip model (Computer Aided Rapid Prototyping-CARP) cerrahi tekniği kullanılmalıdır. ${ }^{26-28}$

f. Kök gelişimini tamamlamış dişler transplantasyonda kullanıldığında pulpa rejenerasyonu sağlanamaz ve kanal tedavisinin yapılması gerekmektedir. Endodontik tedavi, mümkünse dış ortamda yapılmayıp, transplantasyon öncesinde veya sonrasında 1. ve 2. haftalar arasında yapılmalıdır. ${ }^{9,14}$ g. Transplante edilecek dişlerde çürük bulunması, veya önceden yapılmış restoratif veya endodontik tedavi, başarı şansını düşürmektedir. ${ }^{11,} 29$

$\mathrm{Bu}$ maddelere tedaviyi yapacak olan diş hekiminin tecrübesi de eklenebilir. Sonuçta, sıralanan bu kriterlere dikkat edilmediğinde, pulpa nekrozu, durmuş kök gelişimi ve iltihabi kök rezorpsiyonları görülebilmekte ve başarısızlığa neden olunmaktadır. ${ }^{13,17}$

\section{Geleneksel ve yeni tedavi teknikleri}

Klasik cerrahi teknik Andreasen ve arkadaşları tarafından tanımlanmıştır. ${ }^{30}$ Teknik genel olarak donör dişin dikkatli ve zayıf kuvvetler uygulanarak çekilmesini ve kök yüzeyine zarar gelmemesi için önlem alınmasını içermektedir. Alıcı soket, donör dişe uygun olarak cerrahi frezlerle uyumlandırılır ve diş alıcı sokete transplante edilmektedir. Bu cerrahi tekniğin olumsuz tarafı, donör dişin kendisinin alıcı soketi hazırlamak için rehber olarak kullanılması ve tekrarlayan denemeler sonucu hem periodontal membranın zarar görmesi, hem de uyumlandırma süresince geçen zamanın, canlı hücreler aleyhine işlemesidir. Andreasen ve arkadaşları, kuru ortamda 30 dakikadan daha fazla süre bekletildiğinde periodontal membran hücrelerinin canlılı̆ının ciddi bir şekilde azaldığını bildirmişlerdir. 18 dk. bekletildiğinde \%90-100, 30 dk bekletildiğinde

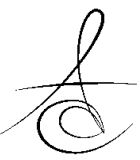


Atatürk Üniv. Diş Hek. Fak. Derg.

J Dent Fac Atatürk Uni

Supplement: 11, Yll: 2015, Sayfa : 114-122
SARUHAN, ERTAŞ, KILINÇ, TEPECİK
\%30-50 olan oran, $120 \mathrm{dk}$ bekletildiğinde \%10-20 olarak bulunmuştur. Fizyolojik salin solüsyonu içerisinde bekletildiğinde ise $30 \mathrm{dk}$. da \%90-100 olan hayatta kalma oranı, $120 \mathrm{dk}$. da \%70-80 olarak bulunmuştur. ${ }^{25}$ Periodontal membran harabiyeti, transplante dişi osteoklastların etkisine maruz bırakarak kök rezorpsiyonuna neden olmaktadır. ${ }^{27}$

Bu olumsuzlukların önüne geçmek için rehber olarak donör dişten başka materyaller kullanılma ihtiyacı doğmaktadır. Bu materyaller, donör diş çekilmeden alıcı yatağı hazırlamakta kullanılabilir ve donör diş çekildikten sonraki uyumlandırma süresi minimale indirilmiş olmaktadır. Bu materyaller, ortalama diş boyutlarında, bakır veya pirinçten üretilmiş rehber maketler, çekilip sterilize edilmiş dişler veya çekilip sterilize edilmiş dişlerin krom-kobalt kopyaları olabilir. ${ }^{31-33} \mathrm{Bu}$ rehber materyallerden, radyografide saptanan donör diş boyutları ile benzer boyutlarda olanları seçilmesi için farklı boyut seçenekleri olmalıdır. Fakat yine de bu yöntemle hazırlanmış alıcı soketler, donör dişin tam boyutlarına göre değil, yaklaşık boyutlarına göre hazırlanmış olacaktır.

Donör dişin tam boyutlarına göre rehber maket hazırlama tekniği bilgisayarlı tomografi ve CAD/CAM sistemleri ile mümkün olmaktadır. Bu sistemler kullanılarak elde edilen bilgi, uygulayıcıya alıcı soket kemik genişlik ve yükseklikleri ile bilgi verirken, anatomik yapılara zarar vermemek için en uygun yeri hesaplamayı da olanaklı hale getirmektedir. ${ }^{19}$

Konik ışınlı bilgisayarlı tomografi (CBCT) destekli ototransplantasyon cerrahisi planlama ve transfer tekniğinin, geleneksel cerrahi teknikle karşılaştırıldığı bir vaka kontrol çalışmasında, CBCT destekli tekniğin, donör dişin ekstraoral koşullarda kalma ve alıcı sokete uyumlandırma süresini azalttığı ve sonuç olarak geleneksel cerrahi yönteme göre daha az komplikasyona neden olduğu bildirilmektedir. ${ }^{26}$ Yine bir vaka raporu, $\mathrm{CBCT}$ ve CAD/CAM tekniği kullanılarak hazırlanan stereolitografik ototransplante diş kopyalarının, alıcı soketi uyumlandırmada kullanıldığında, ototransplantasyon süresini azalttığı ve transplante edilecek dişin periodontal ligamentinin uyumlandırma sırasında daha az hasar gördüğü bildirilmektedir. ${ }^{27}$ CARP kullanılarak alıcı yatakları hazırlanmış dört vakanın sunulduğu bir vaka serisinde, 4 hastada kök gelişimi tamamlanmamış molar dişler ototransplante edilmiş ve 2-7.5 yıl takip edilerek tam kök gelişiminin sağlandığı ve fonksiyonda bir sorun olmadığı bildirilmektedir. Aynı vaka raporunda, ototransplantasyon tedavisinin yüksek başarı oranlarına rağmen, operasyonun karmaşık olması dolayısıyla hekimler tarafından pek uygulanmadığına değinilmiş, endişelerin arkasında prognozun tahmin edilememesi ve ana neden olarak transplante edilecek dişin ekstraoral ortamda kalma süresinin 30 dakikayı geçtiğinde, periodontal hücrelerde geri dönüşümsüz hücre hasarına neden olduğu belirtilmektedir. Alıcı soketin uyumlandırılması sürecinin sadece ekstraoral süreçte artışa neden olmadığı, aynı zamanda, transplante dişin tekrarlanan uyumlandırma denemelerinin periodontal hücrelerde ve HERS'de hasara neden olduğu bildirilmektedir. Araştırıcılar bu problemin çözümü için CARP modelleri kullanımının başarılı sonuçlar verdiğini bildirmektedir. ${ }^{28}$ Konu ile ilgili bir derlemede, СBCT kullanılarak hazırlanan prototip modellerin, uygulama tekniğinde operatör kaynaklı hataları aza indirmesi, transplantın ekstraoral ortamda kalma süresini azaltması ve operatör model kullanıldığında alıc yatak ile transplante diş arasındaki mesafeyi daha uygun koşullarda tutarak hertwig epitel kök kılıfı ve periodontal hücrelerin kan desteğini daha iyi sağlaması gibi nedenlerle, CARP model tekniğinin ototransplantasyon başarısını yükselttiği bildirilmektedir. ${ }^{19}$

\section{Başarı oranı}

Czochrowska ve ark. yaptıkları vaka serisinde; tedaviden sonra kök rezorpsiyonunun yokluğunu, normal durumda sert ve yumuşak periodontal doku görülmesini ve kemik üzeri diş dokusunun kemik içi diş dokularına oranının 1'den az olmasını başarı kriteri olarak almaktadırlar ve 41 yıla kadar takip edilen 25 hastada uygulanmış 30 ototransplante dişin hayatta kalma oranı \%90 olarak bulunurken, söz konusu başarı kriterlerini karşılamadığı için 4 dişi başarısız olarak kabul etmişler ve başarı oranını \%79 olarak kaydetmektedirler. ${ }^{4}$ Jonsson T. ve ark. ortalama 10 yıl takip ettikleri 32 hastada, 40 premolar dişi, karşı çene veya aynı çenede diğer premolar bölgesine transplante etmişler ve \%97.5 hayatta kalma oranı ile \%92.5 başarı oranı kaydetmişler, başarısızlık gösteren 3 dişin birinde kron ve kök kırığı sonrası 4 sene sonra çekim yapıldığı, diğerinde 11 sene sonra yapılan muayenede kötü prognoz, ihmal edilmiş çürük, kron ve kök kırığı ve periapikal lezyon görüldüğü, üçüncü nonvital dişte ise 10 yıl sonra periapikal lezyon görüldüğünü

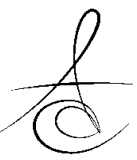


Atatürk Üniv. Diş Hek. Fak. Derg.

J Dent Fac Atatürk Uni

Supplement: 11, Yll: 2015, Sayfa : 114-122
SARUHAN, ERTAŞ, KILINÇ, TEPECİK yaptıkları retrospektif araştırmada bildirmişlerdir. ${ }^{5}$ Bae ve ark. kapalı apeksli ve ortalama yaşı 38.5 olan hasta grubunda 19 molar dişi ototransplante etmişler, ortalama 15 aylık takipte başarı oranını \%84 olarak bulmuşlardır. $^{6}$ Aynı retrospektif araştırmada, araştırıcılar donör dişlerin CARP modelleri kullandıklarını, mineral trioksit agregat (MTA) ile retrograd dolgu yaptıklarını ve periodontal ligament canlıı̆ı̆ın ekstraoral çevreye çıktıktan 18 dakika sonra hızla azaldığını gösteren araştırmalara dikkat çekerek dişlerin, alıcı yatak hazırlanırken salin solüsyonu ile ıslatılmış steril spaçlara sarılarak bekletildiklerine dikkat çekmektedirler.6, 24, 25 Kök formasyonu tamamlanmış üçüncü molarların transplantasyonunu konu eden prospektif bir araştırmada, 50 hastada, 50 üçüncü molar diş, molar bölgelerine transplante edilmiş, 3 hasta takip edilemeyerek 47 diş değerlendirilmiş ve 32 dişte başarılı sonuç elde edilmiştir (\%68). Aynı araştırmada araştırıcılar, alıcı yatağın hazırlanmasında gümüş diş kopya koleksiyonundan donör dişe benzer olanı seçerek kullandıklarını ve kanal tedavisine transplantasyondan 3 ila 4 hafta sonra başladıklarını bildirmişlerdir. ${ }^{7}$ Akkocaoğlu ve ark. 72 hastada 96 kök gelişimi tamamlanmış veya tamamlanmaya yakın maksiller kanin ve mandibuler üçüncü molar dişleri ototransplante etmiş, primer splint stabilizasyon kullanmamış, 10 yıllık takip sonrası 83 dişte (\%86) başarı elde ettiklerini bildirmektedirler. ${ }^{8}$ Bauss 0 . ve arkadaşlarının bildirdikleri vaka serisinde, ortalama 17.7 yaşında (16.1-20.3 yaş aralığı) olan 79 hastada 85 kök gelişimi tamamlanmamış üçüncü molar dişler ototransplante edilmiştir. Araştırıcılar hazırladıkları alıcı yatakları, atrofik alveolde kemik otogrefti kullanımı, split osteotomi ve hazırlanmış soketler olarak 3 deney grubuna ve taze çekim soketleri olarak 1 kontrol grubuna ayırmışlar ve toplam başarı oranını \%86 olarak bulduklarını bildirmektedirler $(n=73)$. Araştırıcılar, split osteotomi grubunun kontrol grubu ile karşılaştırıldığında pulpa tıkanması açısından ve duraklamış kök gelişimi açısından düşük sonuçlar vererek anlamlı bir fark oluşturduğunu bildirmektedirler. $^{34}$ Yan ve ark. kök gelişimi tamamlanmış ve tamamlanmamış toplam 35 mandibuler üçüncü molar dişi, aynı veya kontralateral kadrandaki taze çekim soketlerine ototransplante etmiş ve ortalama 5.2 yıl takipte 33 dişte başarılı olduklarını bildirmektedirler. ${ }^{35}$

Başarı oranlarını araştıran birçok çalışma mevcut olmakla birlikte elde edilen başarı oranları arasında farklııklar bulunmaktadır. $\mathrm{Bu}$ farklııklar; dişlerin apekslerinin kapalı olup olmamasına, diş köklerinin gelişim evrelerine göre değişiklik göstermektedir (Tablo 1). Özellikle Plakwicz ve ark. 2013 yılında, açık apeksli dişlerle yaptıkları çalışmada hayatta kalma oranını \%100 olarak bildirmişlerdir. ${ }^{36}$

\section{Prognostik faktörler ve Kök rezorpsiyonu}

Kök gelişimini tamamlamış dişlerin ototransplantasyon başarısını etkileyen prognostik faktörleri konu edinmiş bir klinik araştırmada 117 ototransplante edilmiş diş ortalama 40.9 ay takip edilmiş ve 14 'ü başarısız bulunmuştur. 14 dişten 5 'inde erken iyileşme başarısızlığı, 5'inde replasman kök rezorpsiyonu ve periodontal iltihap, kalan 4 dişte ise her biri ayrı bir diş için, kemik rejenerasyon gecikmesi, kök fraktürü, transplante edilen dişin periapikal veya periodontal iltihabı sebebiyle oluşan maksiller sinüzit ve diğer nedenlerle başarısız transplantasyon nedenleri bildirilmiştir. Yapılan tek faktör analizinde genç yaş iyi prognozla ilişkilendirilirken, donör dişte $4 \mathrm{~mm}$ veya daha fazla periodontal cep varlığı ve donör dişte kök kanalı tedavisi öyküsü kötü prognozla ilişkilendirilmiştir. ${ }^{11}$ Kim ve ark. kök gelişimi tamamlanmış 182 transplante edilmiş vakayı farklı sürelerde takip etmişler, ilk stabilite ve dişlerin ekstraoral ortamda kalma süreleri ile başarı oranlarını karşılaştırmışlardır. 2-4 aylık periyotta takibe gelen hastalarda, primer stabilitesi iyi olan grubun kötü olan gruba göre anlamlı derecede iyi iyileşme gösterdiği belirtilirken, 5-7 aylık ile 8 ay ve sonrası periyottaki kontrollerde, primer stabilitenin iyileşme üzerine anlamlı bir etkisi olmadığını bildirmektedirler. Ankiloz ve kök rezorpsiyonu gösteren vakalarla dişlerin ekstraoral ortamda kalma süreleri analiz edilmiş ve ekstraoral ortamda kalma süresi ile ankiloz veya kök rezorpsiyonu oluşması arasında anlamlı bir ilişki bulunmadığı bildirilmektedir. ${ }^{37}$ Kim ve ark. yaptıkları bu çalışmaya yönelik yayımlanan bir makale analizinde, çalışmadan ayrılan yüksek hasta grubuna ve her dişe gereksizce uygulanan kanal tedavisine ve bir durumda da 9 dişin transplantasyon sırasında kanal tedavisinin apikoektomi ile beraber kombine edilmiş olmasına ve ortalama süre olarak $15.36 \mathrm{dk}$ verilmesine dikkat çekilmiş ve başka yönlerden de birçok eleştiri yapılarak çalışmanın zayıf olduğu bildirilmiştir. ${ }^{38}$ Kallu ve ark. klinik kriterler ile başarı oranını karşılaştırdığı, 194 
Atatürk Üniv. Diş Hek. Fak. Derg.

] Dent Fac Atatürk Uni

Supplement: 11, Yıl: 2015, Sayfa : 114-122
SARUHAN, ERTAŞ, KILINÇ, TEPECIKK hastada 273 dişin ototransplante edildiği retrospektif araştırmada, 58 dişte değişik düzey ve tipte rezorpsiyon görülmüş, 37 diş ise ankiloza uğramış, 15 dişte hem kök rezorpsiyonu hem ankiloz görülmüş, kök rezorpsiyonu ve ankilozun başarısızlıktaki en büyük etken olduğu vurgulanmıştır. Bir araştırmada, ototransplante edilen kanin dişlerinin ve kök gelişimini tamamlamış dişlerin en çok kök rezorpsiyonuna ve ankiloza uğrayan gruplar olduğu belirtilmiş ve transplantasyon sırasındaki kök uzunlukları olması gerekenden $1 / 2$ ve $3 / 4$ uzunluğunda olan dişlerin de anlamlı derecede yüksek başarı sağladıkları yine aynı araştırmada bildirilmektedir. ${ }^{12}$ Azevedo ve ark. köpekler üzerinde, kapalı apeksli diş transplantasyonlarının endodontik tedavi zamanlamasını araştırdıkları bir deneysel araştırmada, endodontik tedavinin 40 güne kadar ertelenebileceğini bildirmektedirler. $^{39}$ Kök gelişimi tamamlanmış ototransplante dişlerde görülen kök rezorpsiyonunun donör diş özellikleri ile ilişkisini konu edinen bir araştırmada, 110 hastada 117 diş ototransplante edilmiş, 1 yıl takip edilmiş ve 20 dişte başarısızlık görülmüştür. 20 dişin 11'inde hızı ilerleyen kök rezorpsiyonu, beş dişte erken iyileşme başarısızlığı görülmüştür. Tüm hızlı ilerleyen kök rezorpsiyonu görülen donör dişlerde 4 mm'den daha fazla periodontal cep derinliği, diş çürükleri, restorasyon hikayesi ve endodontik tedavi hikayesi faktörlerinden en az birisinin bulunduğu, başarılı olan vakalarda bu faktörlerin hiç birisinin bulunmadığı bildirilmiştir. Araştırıcılar transplante edilecek dişlerde bu faktörlerden birinin varlığında, başka bir donör dişin transplantasyon için düşünülmesi gerektiğini, eğer kullanılacaksa yakından takip edilmesi gerektiğini önermektedirler. ${ }^{29}$ Waikakul ve ark. 1, 3, 6, 9 ve 12 aylık periyotlarda radyografik olarak değerlendirdikleri 54 diş transplantasyonunda, araştırdıkları dişlerin \%89'unda üçüncü ayda tam kemik iyileşmesi, \%63'ünde altınca ayda lamina dura gelişimi gözlendiğini bildirmektedirler. Araştırmacılar bu sonuçlara dayanarak, üçüncü molar diş transplantasyonlarının üç ay içinde çiğneme yükünü karşılayabileceği sonucuna varmaktadırlar. ${ }^{40}$ Aoyama ve ark. kök gelişimini tamamlamış ototransplante dişler üzerinde prognostik faktörleri inceledikleri bir araştırmada, 259 diş transplantasyonundan 27 dişte başarısızlık bulmuşlardır. Bu başarısızlıklar tek varyant analizde, hastanın 40 yaşın üzerinde olması, donör dişin maksilladan çekilmesi, donör dişin molar diş olması, $4 \mathrm{~mm}$ ve üzerindeki periodontal cep derinlikleri, donör dişin çürüğü/restorasyonu, endodontik tedavi öyküsünün olması, çok köklü dişler, diverjan köklü dişler, alıcı soketin 2.5 ay dişsiz kalması, karşı çeneye diş transplantasyonu olarak kaydedilmiş ve başarısızlıkla ilişkilendirilen önemli faktörler olarak bildirilmektedirler. ${ }^{41}$

Fibroblast büyüme faktörü (FGF-2) ile ototransplante dişlerde kök rezorpsiyonu ilişkisini araştıran bir hayvan deneyinde, köpek premolarları, 2 ay önce çekilmiş premolar dişler bölgesine ototransplante edilmiş ve bu dişler transplante edilmeden önce hava ile kurutulmuştur. Deney grubu dişlerine FGF-2 uygulanırken, kontrol grubuna uygulanmamış ve hayvanlar ikinci, dördüncü veya sekizinci haftada öldürülüp, ototransplante dişlerden kesitler histolojik olarak incelenmiştir. İkinci haftada dentin rezorpsiyonunun kontrol grubunda anlamlı derecede yüksek olduğu görülürken, hiçbir grupta replasman rezorpsiyonu görülmemiştir. Dördüncü haftada deney grubunda periodontal ligament benzeri doku görüldüğü ve sementten alveol kemiğine uzanan bağ dokusu fibrilleri gözlendiği bildirilirken, kontrol grubunda kök rezorpsiyonu görüldüğü ve fibrillerin diş yüzeyine paralel seyrettiği veya alanın multinükleer hücrelerden bol olarak aktif dentin rezorpsiyonu sahası olarak görüldüğü bildirilmiştir. Sekizinci haftada kök etrafının tamamen yeni oluşmuş kemikle çevrili olduğu, kök yüzeyi ile sement arasında periodontal ligamentin belirgin bir şekilde görüldüğü bildirilmiş, kontrol grubunda ise replasman rezorpsiyonu gözlendiği bildirilmektedir. Dört ve sekizinci haftalarda, replasman kök rezorpsiyonunun kontrol grubunda anlamlı şekilde yüksek olduğu vurgulanmış, FGF-2 nin periodontal dokunun hasarlandığı durumlarda replasman rezorpsiyonunu önleyebileceği bildirilmiştir. ${ }^{42}$

\section{teknikleri \\ Oroantral ilişki ve farklı osteotomi}

Oroantral ilişkinin diş ototransplantasyonları ile kapatıldığı vaka raporları da yayınlanmıştır. Maksiller molarları çekildikten sonra sinüs membran perforasyonu ile birlikte oroantral ilişki oluşan iki hastanın vaka raporunda, araştırıcılar maksiller üçüncü molarları çekip, çekilen bölgeye ototransplante etmişler, 2 yıllık takipten sonra bilgisayarlı tomografide diş kökü etrafında yeni kemik oluşumu gözlediklerini bildirmişlerdir. Hastaların dişlerinde kök rezorpsiyonu ve fonksiyonda 
Atatürk Üniv. Diş Hek. Fak. Derg.

J Dent Fac Atatürk Uni

Supplement: 11, Yll: 2015, Sayfa : 114-122

bir patolojinin bulunmadığı da gözlenmiştir. ${ }^{43}$ Yatay kemik kalınlığının uygun, fakat maksiller sinüs ile dikey alveol kemik mesafesinin yetersiz olduğu vakalarda, kemik ogmentasyonu ile birlikte ototransplantasyon yapılarak sinüs tabanı yükseltmesini anlatan bir teknik raporda, yapılan takipler sonucu diş kökü etrafında yeni oluşmuş kemik dokusunun görüldüğü ve dişlerin iyi fonksiyonda olduğu bildirilmektedir. ${ }^{4}$ Sağ maksiller sinüs pnömatizasyonu mevcut olan bir hastada, mandibuler sağ üçüncü molar, geleneksel yöntemle endodontik tedavisi yapılarak çekilmiştir. Sağ maksillada sinüs membranı, yan ve alt duvarından tamamen ayrılmış, ototransplantasyonu yapılacak dişin önceden hazırlanan bilgisayar destekli hızlı prototip (CARP) kopyası, sağ maksillada alıcı yatak hazırlamak için kullanılarak alııı soket hazırlanmıştır. Sığır kaynakı hidroksiapatit, sinüs kavitesi içine yerleştirilmiş, ve diş ototransplante edilmiştir. 4 yıllık kontroller sonrasında, dişte herhangi bir hareketlilik, kök rezorpsiyonu veya ankiloz görülmediği, sadece mezial bölgede 5 mm'lik periodontal cep varliğının olduğu ve hastanın tedaviden memnun olduğu bildirilmiştir. ${ }^{45}$ Osteotom sinüs tabanı yükseltmesi ve beta-trikalsiyum fosfat ogmentasyonu kullanılarak, maksiller sağ üçüncü molar dişin, alveol kemik yüksekliği $2 \mathrm{~mm}$ olan maksiller sol birinci molar diş bölgesine ototransplantasyonunu konu eden bir vaka raporunda, 38 yaşındaki erkek hasta 42 ay boyunca takip edilmiştir. Yapılan bilgisayarlı tomografi değerlendirmesinde transplante edilen diş çevresinde kemik rejenerasyonu gözlendiği bildirilmiştir. Araştıııılar sinüs membranı kalınlaşması, iltihap ve kök rezorpsiyonu görmediklerini kaydetmişlerdir. ${ }^{46}$

Kök gelişimi henüz tamamlanmamış üçüncü molar dişlerin ototransplantasyonunda, farklı cerrahi tekniklerin, kök gelişimine etkisi araştııılmışıı. Bu amaçla 88 hastada 90 üçüncü molar diş ototransplante edilmiştir. Dikey alveol mesafesi yetersizliklerinde serbest kemik grefti kullanılmış, yatay alveol kalınlığı yetersizliklerinde ise split osteotomi tekniği kullanılmıştır. Bir grup ise ek bir cerrahi teknik uygulanmadan yeni çekim soketlerine transplante edilerek kontrol grubu olarak araştırmaya dahil edilmiştir. Post operatif takip döneminde dişlerin kök gelişimlerine en fazla olanak tanıyan tekniğin kontrol grubunda olduğu görülmüştür. En olumsuz sonuçlar split osteotomi grubunda görülürken, kemik otogreft grubunun, her iki grupla ilişkisi anlamsız bulunmuştur. Bu durumda, split
SARUHAN, ERTAŞ, KILINÇ, TEPECİK

osteotomi tekniğinin, açık apeksli dişlerin pulpa revaskülarizasyonu ve kök gelişimine olumsuz etkisi olduğu sonucuna varmışlardır. ${ }^{47}$

\section{SONUÇ}

Sonuç olarak, ototransplantasyon, doğru endikasyonu olan hastada, diş eksikliğinin biyolojik avantajlar açısından en uygun tedavi şeklidir. Prognostik faktörlere dikkat edildiğinde başarı oranı yüksektir. Değişik tiplerde kök rezorpsiyonları ve ankiloz ototransplante dişlerde görülen en yaygın komplikasyonlardır ve başarısız ototransplantasyon nedenleri arasında periodontal hastalıklı ve kanal tedavili donör dişlerin etkisi yüksektir. Bununla beraber CARP model tekniği ototransplante dişlerin alıcı yatak uyumunu sağladığı ve ekstraoral ortamda kalma süresini azalttığı için konvansiyonel tekniğe göre avantajlı bir tekniktir.

\section{KAYNAKLAR}

1. Apfel H. Autoplasty of enucleated prefunctional third molars. Journal of Oral Surgery 1950;8:28996.

2. Miller HM. Transplantation; a case report. Journal of the American Dental Association 1950;40:237, illust.

3. Miller HM. Transplantation and reimplantation of teeth. Oral Surg Oral Med and Oral Pathol 1956;9:84-95.

4. Czochrowska EM, Stenvik A, Bjercke B, Zachrisson BU. Outcome of tooth transplantation: survival and success rates 17-41 years posttreatment. Am J of Orthod and Dentofac Orthop 2002;121:110-9

5. Jonsson T, Sigurdsson TJ. Autotransplantation of premolars to premolar sites. A long-term follow-up study of 40 consecutive patients. American journal of orthodontics and dentofacial orthopedics : 2004; 125:668-75.

6. Bae JH, Choi YH, Cho BH, Kim YK, Kim SG. Autotransplantation of teeth with complete root formation: a case series. Journal of Endod 2010;36422-6.

7. Mejare B, Wannfors $K$, Jansson L. A prospective study on transplantation of third molars with complete root formation. Oral Surg Oral Med Oral Pathol Oral Radiol And Endod 2004;97:231-8. 
Atatürk Üniv. Diş Hek. Fak. Derg.

J Dent Fac Atatürk Uni

Supplement: 11, Yll: 2015, Sayfa : 114-122
SARUHAN, ERTAŞ, KILINÇ, TEPECIK
8. Akkocaoglu M, Kasaboglu O. Success rate of autotransplanted teeth without stabilisation by splints: a long-term clinical and radiological followup. The $\mathrm{Br}$ J Of Oral \& Maxillofac Surg 2005; 43:31-5.

9. Tsukiboshi M. Autotransplantation of teeth: requirements for predictable success. Dent Traumatol 2002; 18: 157-80.

10. Kumar R, Khambete N, Priya E. Successful immediate autotransplantation of tooth with incomplete root formation: case report. Oral Surg Oral Med Oral Pathol Oral Radiol 2013;115:e1621.

11. Sugai T, Yoshizawa M, Kobayashi T, Ono K, Takagi $\mathrm{R}$, Kitamura $\mathrm{N}$, et al. Clinical study on prognostic factors for autotransplantation of teeth with complete root formation. Int J of Oral and Maxillofac Surg 2010;39:1193-203.

12. Kallu R, Vinckier F, Politis C, Mwalili S, Willems G. Tooth transplantations: a descriptive retrospective study. Int $\mathrm{J}$ of oral and Maxillofac Surg 2005;34:745-55.

13. Lundberg $\mathrm{T}$, Isaksson $\mathrm{S}$. A clinical follow-up study of 278 autotransplanted teeth. $\mathrm{Br}$ J Oral Maxillofac Surg 1996;34:181-5.

14. Gonnissen H, Politis C, Schepers S, Lambrichts I, Vrielinck $L$, Sun $Y$, et al. Long-term success and survival rates of autogenously transplanted canines. Oral Surg Oral Med Oral Pathol Oral Radiol Endod 2010;110:570-8.

15. Natiella JR, Armitage JE, Greene GW. The replantation and transplantation of teeth. A review. Oral Surg Oral Med Oral Pathol 1970;29:397-419.

16. Tsukiboshi M, Andreasen JO. Autotransplantation of teeth: Quintessence Pub Co; 2001.

17. Schwartz O, Bergmann P, Klausen B. Autotransplantation of human teeth. A life-table analysis of prognostic factors. Int J Oral Surg 1985;14:245-58.

18. Smith JJ, Wayman BE. Successful autotransplantation. J Endod 1987;13(2):77-80.

19. Cross D, El-Angbawi A, McLaughlin P, Keightley A, Brocklebank L, Whitters J, et al. Developments in autotransplantation of teeth. The surgeon : Journal of the Royal Colleges of Surgeons of Edinburgh and Ireland 2013;11:49-55.
20. Zachrisson BU, Stenvik A, Haanaes HR. Management of missing maxillary anterior teeth with emphasis on autotransplantation. Am J Orthod Dentofacial Orthop 2004;126:284-8.

21. Tanaka T, Deguchi T, Kageyama T, Kanomi R, Inoue $\mathrm{M}$, Foong KW. Autotransplantation of 28 premolar donor teeth in 24 orthodontic patients. Angle Orthod 2008;78:12-9.

22. Vilhjalmsson VH, Knudsen GC, Grung B, Bardsen A. Dental auto-transplantation to anterior maxillary sites. Dent Traumatol 2011;27:23-9.

23. Sabuncuoglu FA, Uzun SA. Immediate autotransplantation of mandibular canine (a case report). Ataturk Univ Dis Hek Fak Derg 2012;5:203.

24. Andreasen JO. Periodontal healing after replantation and autotransplantation of incisors in monkeys. Int J of Oral Surg 1981;10:54-61.

25. Andreasen JO. Effect of extra-alveolar period and storage media upon periodontal and pulpal healing after replantation of mature permanent incisors in monkeys. Int J of Oral Surg 1981;10:43-53.

26. Shahbazian M, Jacobs R, Wyatt J, Denys D, Lambrichts I, Vinckier $F$, et al. Validation of the cone beam computed tomography-based stereolithographic surgical guide aiding autotransplantation of teeth: clinical case-control study. Oral Surg Oral Med Oral Pathol Oral Radiol 2013;115:667-75.

27. Honda M, Uehara $H$, Uehara T, Honda $K$, Kawashima S, Yonehara Y. Use of a replica graft tooth for evaluation before autotransplantation of a tooth. A CAD/CAM model produced using dentalcone-beam computed tomography. International journal of oral and maxillofacial surgery 2010;39:1016-9.

28. Jang JH, Lee SJ, Kim E. Autotransplantation of immature third molars using a computer-aided rapid prototyping model: a report of 4 cases. J Endod 2013;39:1461-6.

29. Kanae Niimi MY, Toshiko Sugai, Tadaharu Kobayashi, Kazuhiro Ono, Ritsuo Takagi, Tkashi Okiji, Chikara Saito. Clinical study on root resorption of autotransplanted teeth with complete root formation. Asian Journal of Oral and Maxillofac Surg 2011. 
Atatürk Üniv. Diş Hek. Fak. Derg.

J Dent Fac Atatürk Uni

Supplement: 11, Yll: 2015, Sayfa : 114-122
SARUHAN, ERTAŞ, KILINÇ, TEPECIK
30. Andreasen JO, Paulsen HU, Yu Z, Ahlquist R, Bayer T, Schwartz O. A long-term study of 370 autotransplanted premolars. Part I. Surgical procedures and standardized techniques for monitoring healing. Eur J Orthod 1990;12:3-13.

31. Meechan JG, Carter NE, Gillgrass TJ, Hobson RS, Jepson NJ, Nohl FS, et al. Interdisciplinary Management of Hypodontia: Oral Surgery. Br Dent J 2003;194:423-7.

32. Kugelberg $R$, Tegsjo $U$, Malmgren $O$. Autotransplantation of 45 teeth to the upper incisor region in adolescents. Swed Dent J 1994;18:165-72.

33. Day PF, Lewis BR, Spencer RJ, Barber SK, Duggal $M$. The design and development of surgical templates for premolar transplants in adolescents. Int Endod J 2012;45:1042-52.

34. Bauss O, Engelke W, Fenske C, Schilke R, Schwestka-Polly R. Autotransplantation of immature third molars into edentulous and atrophied jaw sections. Int J Oral and Maxillofac Surg 2004;33:558-63.

35. Yan Q, Li B, Long X. Immediate autotransplantation of mandibular third molar in China. Oral surgery, oral medicine, oral pathology, oral radiology, and endodontics 2010;110:436-40.

36. Plakwicz P, Wojtowicz A, Czochrowska EM. Survival and success rates of autotransplanted premolars: a prospective study of the protocol for developing teeth. Am J Orthod Dentofac Orthop 2013;144:229-37.

37. Kim E, Jung JY, Cha IH, Kum KY, Lee SJ. Evaluation of the prognosis and causes of failure in 182 cases of autogenous tooth transplantation. Oral Surg Oral Med Oral Pathol Oral Radiol and Endod 2005;100:112-9.

38. Pogrel MA. Unclear prognosis for the autogenous tooth transplant. The Journal of Evidence-Based Dental Practice 2006;6:271-3.

39. Azevedo PC, Moura CC, Zanetta-Barbosa D, Bernadineli N. Time of endodontic treatment in autogenic transplants of mature teeth: histological study in dogs. Oral Surg Oral Med Oral Pathol Oral Radiol and Endod 2007;104:287-93.
40. Waikakul A, Punwutikorn J, Kasetsuwan J, Korsuwannawong $\mathrm{S}$. Alveolar bone changes in autogenous tooth transplantation. Oral Surg Oral Med Oral Pathol Oral Radiol and Endod 2011;111:e1-7.

41. Aoyama S, Yoshizawa M, Niimi K, Sugai T, Kitamura N, Saito C. Prognostic factors for autotransplantation of teeth with complete root formation. Oral Surg Oral Med Oral Pathol and Oral Radiol 2012;114:S216-28.

42. Shiratani S, Ota M, Fujita T, Seshima F, Yamada S, Saito A. Effect of basic fibroblast growth factor on root resorption after delayed autotransplantation of tooth in dogs Oral Surg Oral Med Oral Pathol and Oral Radiol 2012;114:e14-21.

43. Kitagawa Y, Sano K, Nakamura M, Ogasawara T. Use of third molar transplantation for closure of the oroantral communication after tooth extraction: a report of 2 cases. Oral Surg Oral Med Oral Pathol Oral Radiol and Endod 2003;95:40915.

44. Shinya Yura NF, Takumi Kato, Noritaka Ohga, Kazuhiro Ooi, Yuri Izumiyama. Procedure for Tooth Autotransplantation with Bone-added Sinus Floor Elevation. Asian J of Oral and Maxillofac Surg 2009;21:106-08.

45. Park YS, Baek SH, Lee WC, Kum KY, Shon WJ. Autotransplantation with simultaneous sinus floor elevation. J of Endod 2012;38:121-4.

46. Koichi Yoshino YT, Yasushi Yoda, Takashi Matsukubo. Autotransplantation of tooth by osteotome sinus floor elevation technique with beta-tricalcium phosphate. Journal of Oral and Maxillofac Surg Med and Pathol 2013;25:351-4.

47. Bauss O, Zonios I, Engelke W. Effect of additional surgical procedures on root development of transplanted immature third molars. Int J of Oral and Maxillofac Surg 2008;37:730-5.

\section{Yazışma Adresi}

Arş. Gör. Dt. Tahsin TEPECİK

Atatürk Üniversitesi,

Diş Hekimliği Fakültesi,

Ağız, Diş ve Çene Cerrahisi A.B.D.,

Erzurum, Türkiye

Tel.: 09044223609 441-1747,

e-mail:tahsintepecik@gmail.com 